\title{
The application of Raman spectroscopy and chemometric methods for analysis healthy blood and blood with BRCA mutation
}

\section{Kopec ${ }^{1}$, B. Romanowska-Pietrasiak ${ }^{2}$, H. Abramczyk*1}

* Correspondence: Halina Abramczyk, halina.abramczyk@p.lodz.pl

${ }^{1}$ Lodz University of Technology, Institute of Applied Radiation Chemistry, Laboratory of Laser Molecular Spectroscopy, Wroblewskiego 15, 93-590 Lodz, Poland

${ }^{2}$ Oncological Surgery Department, Copernicus Provincial Multidisciplinary Centre of Oncology and Traumatology in Lodz, Medical Genetics Department, Copernicus Provincial Multidisciplinary Centre of Oncology and Traumatology in Lodz, Pabianicka 62, 93-513 Lodz, Poland

\section{Graphical Abstract}

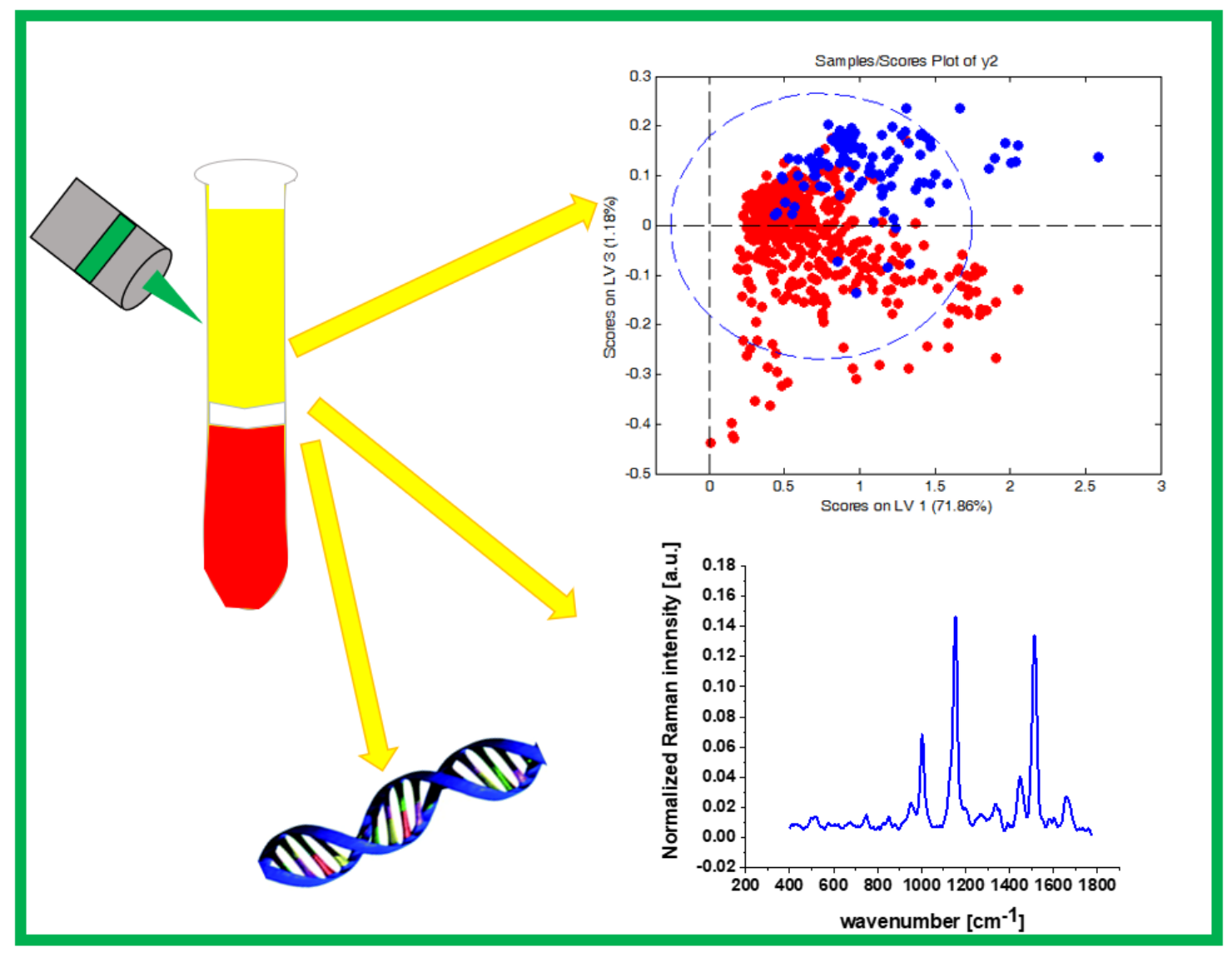

\section{Abstract}


Presented study included human blood from heathy patients and from patients with BRCA mutation. Raman spectroscopy can be used for BRCA mutation detection and bioanalytical characterization of pathologically changed samples. The aim of this study is to evaluate the Raman biomarkers to distinguish blood samples from healthy patients and from patient with BRCA mutation by Raman spectroscopy. We have proved that Raman spectroscopy is a powerful technique to distinguish between healthy blood and blood with BRCA mutation and to characterize biochemical composition of samples. Partial Least Squares Discriminant Analysis yielded effective and comparable samples classification based on vibrational features. The sensitivity and specificity obtained from PLS-DA have been over $86.5 \%$. The obtained results confirm clinical potential of Raman spectroscopy in oncological diagnostics.

\section{Key words}

Raman spectroscopy, human blood plasma, BRCA mutation, PLS-DA

\section{Introduction}

Blood is important fluid that circulate through the body and has a lot of functions that are fundamental for surviving [1] The first function of blood is transportation with supplying oxygen to all cells and tissues. Moreover, blood supplies essential substances to cells, such as sugars or hormones and removes waste products from cells. [2] Second function is regulation such as body right temperature or concentration each of the components of the blood [3]. Third function of blood is protecting the body from diseases and infections. [2] [3] [4] Blood transfers a lot of molecular information and reflects real health based on metabolism. [5] In blood there is a lot of biomarkers that can be useful tool for characterizing pathology processes including cancer. [6] [7] [8] [9] [10] Blood marker analysis may help identify early stages of pathological processes that can lead to future serious diseases. [11]

Breast cancer is one of the most common cancer in population. Moreover it is the most common cause of cancer death. [12] Breast cancer genes (BRCA) belong to the group which produce proteins that help repair DNA. [13] [14] People who inherit pathogenic modifications of BRCA have increased risk of cancers, especially breast cancer. [15] [16] There are studies demonstrating that tumor grade correlates with the level of BRCA proteins. [17]

The potential of BRCA proteins expression in breast cancer has been studied by numerous groups. [18] [19] [20] [21] [22] [23] [6] E. Gross et al. have used chromatography to study 
BRCA mutation. [24] They have compared results for BRCA mutation obtained by direct sequencing method with results obtained by high performance liquid chromatography (DHPLC). They reported that DHPLC is fast, sensitive and powerful method for genetic analysis. [24] [25] J. Roth et al. have used Ultra HPLC with Tandem Mass Spectrometric Detection (uHPLC-MS/MS) to analyse activity Olaparib in human plasma. [26]

Recently next generation sequencing (NGS) technologies have been widely used for BRCA mutation analysis. [27] [28] E. Szczerba et al. have studied BRCA mutation in the tumor tissue using NGS. [29] They used bioinformatic-NGS software programs to analyse BRCA. [29] [21] NGS procedures can become an invaluable tool for clinical diagnosis in the near future .

The BRCA gene test is a standard method used for people who have an inherited mutation based on family history. The results of this method aren't always clear. So it is justified to find new methods for detection and treatment of early-stage disease. This hope may be provided Raman spectroscopy. To the best of our knowledge it is only few paper described using Raman spectroscopy to study BRCA mutation. L.R. Allain et al. for the first time have used SERS to monitor DNA hybridization of a fragment of the BRCA1 breast cancer susceptibility gene on modified silver surfaces. [30] They proved that SERS technique for gene expression studies is a significant step forward in enabling biological quantification. [30] Another group which used SERS to analyze BRCA mutation was M. Culha et al. [31] Raman spectroscopy is a tool that provides information about biochemical composition of organelles in single cells. Raman spectroscopy allows to identifying cancer biomarkers which can discriminate between normal state and cancer pathology.

In this paper, we present that Raman spectroscopy combined with statistical methods of artificial intelligence made possible to discriminate between healthy patients and patient with BRCA mutation by testing human blood plasma

In this paper, we focus on the analysis of Raman spectra of blood plasma from patients without BRCA mutations (control) and patients with BRCA mutations using the optimal multivariate methods to differentiate between samples. Raman spectroscopy gives a new promise to provide a perfect tool for BRCA mutation diagnosis.

\section{Materials and methods}




\section{Sample preparation}

The blood samples were obtained from the Voivodeship Multi-Specialist Center for Oncology and Traumatology in Lodz. The procedure did not affects the course of the treatment of the patients. Written informed consent was obtained from all patients, or if subjects are under 18, from a parent and/or legal guardian. All experiments were conducted in accordance with relevant guidelines and regulations of the Bioethical Committee at the Medical University of Lodz, Poland (RNN/17/20/KE). The experimental protocols were approved by Bioethical Committee at the Medical University of Lodz, Poland (RNN/17/20/KE). All the experiments were carried out in accordance with Good Clinical Practice and with the ethical principles of the Declaration of Helsinki. Spectroscopic analysis did not affect the scope of course and type of undertaken hospital treatment.

Patients with BRCA mutation were diagnosed and treated at the Voivodeship Multi-Specialist Center for Oncology and Traumatology in. For all experiments we used human fresh blood. Blood samples were collected in Ethylene Diamine Tetra Acetic Acid (EDTA) vials and next centrifuged at $3500 \mathrm{rpm}$ for $5 \mathrm{~min}$ in $18^{\circ} \mathrm{C}$ to yield the plasma samples. A $10 \mu \mathrm{l}$ drop of each plasma blood was placed on clean $\mathrm{CaF} 2$ windows (Crystran).

\section{Raman spectroscopy}

The Raman measurements were recorded using an alpha 300 RSA+ (WITec, Germany) combined with confocal microscope coupled via the fiber of $50 \mu \mathrm{m}$ core diameter with a spectrometer UHTS (Ultra High Throughput Spectrometer) and a CCD Camera (Andor Newton DU970N-UVB-353) operating in standard mode with $1600 \times 200$ pixels at $-60{ }^{\circ} \mathrm{C}$ with full vertical binning. Standard calibration procedure was performed every day before measurement with the use of silicon plate $\left(520.7 \square \mathrm{cm}^{-1}\right)$. Raman data were pre-processed were performed using the WITec Project Plus Software. Each Raman spectra were processed to remove cosmic rays. The corrected Raman spectra were smoothed by a Savitzky and Golay procedure and baseline subtraction. All experiment were performed using laser beam (SHG of the Nd:YAG laser $(532 \mathrm{~nm})$ ) and 40x dry objective (Nikon, objective type CFI Plan Fluor CELWD DIC-M, numerical aperture (NA) of 0.60 and a 3.6-2.8 mm working distance). Raman spectra for plasma blood samples were recorded using integration time 1 and 10 number of accumulations. All experiments were performed using laser with a power was 10 $\mathrm{mW}$ at the sample position. 
The background subtraction and the normalization (model: divided by norm (divide the spectrum by the dataset norm)) were performed by using Origin software. The normalization model: divided by norm was performed according to the formula:

$$
\begin{gathered}
V^{\prime}=\frac{V}{\|V\|} \\
\|V\|=\sqrt{v_{1}^{2}+v_{2}^{2}+\cdots v_{n}^{2}}
\end{gathered}
$$

where:

$v_{n}$ is the $\mathrm{n}^{\text {th }} \mathrm{V}$ values. [32]

The normalization was performed for spectral region $\left(400-1700 \mathrm{~cm}^{-1}\right)$

\section{Molecular methods for the detection of BRCA1 and BRCA2 germline mutations}

Molecular diagnosis of genetic disorders is defined as searching for and revealing defects in DNA and/or RNA samples. Detection of mutations in the BRCA1 and BRCA2 genes involves several sequencing procedures. The methods for identification of the disease-causing mutations can be classified as methods for detection of known mutations and those unknown [33] [34] [35].

\section{First procedure}

The first step in performing DNA extraction is sampling (blood, saliva or tissue specimens, etc.). Peripheral blood (most frequently used to obtain DNA for human genetic studies) can be obtained using tubes treated with EDTA or Sodium Citrate to prevent clotting. Then, the human genomic DNA is isolated from fresh or frozen blood or cells and identified, isolated and subsequently purificated $[36,37]$

\section{$\underline{\text { Second procedure }}$}

In families carrying a pathogenic variant in BRCA1 and BRCA2 genes usually Sanger sequencing method has been used for detecting them. It is the gold-standard DNA sequencing technique. This method is based on the selective incorporation of chain-terminating dideoxynucleotides by DNA polymerase during in vitro DNA replication. Traditional Sanger sequencing is restricted to the discovery of small defects (substitutions, insertions, deletions). This technology plays a major role in verification of PCR results $[38,39]$

\section{Third procedure}


The third stage of testing is screening for the point known mutations. Polish studies showed that the BRCA1 founder effect exist with a predominant presence of variants such as c.5266dupC, c.181T>G， c.4035delA， c.68_69delAG， c.3700_3704delGTAAA， but the mutations spectrum is more heterogeneous. The main technique dedicated to the detection of known mutations in BRCA1 and BRCA2 is the polymerase chain reaction (PCR) and its variations, for example Real Time PCR. This method is characterized by high sensitivity and specificity [40-42]

Fourth procedure

In clinical cases of high probability of unknown mutations identification the next-generation sequencing (NGS) technique is used. This is a new technology used for DNA and RNA sequencing and detection of different types of genes mutations such as known, unknown, founder or recurrent [43-45].

\section{$\underline{\text { Fifth procedure }}$}

The exons deletions or amplifications related cases of hereditary breast cancer might not be detected by sequence analysis. In that case another molecular diagnostic technique should be used. Multiplex Ligation-dependent Probe Amplification (MLPA) offers the possibility to detect large genomic rearrangements [46-49].

\section{Statistical analysis}

We have analyzed samples with BRCA mutation from 85 patients and samples from control patients without BRCA mutations from 15 patients. In total, samples from 100 patients have been analyzed. In detail, for samples with BRCA mutations we used typically 460 Raman single spectra, for samples from healthy patients we used 104 Raman spectra.

Statistical chemometric analysis was performed by using Mathlab and PLS_Toolbox Version 4.0. Partial Least Squares Discriminant Analysis (PLSDA) was used for building predictive classification models, to validate the classification models and to calculate sensitivity and specificity. A ROC curve analysis has also been performed. More details about chemometric methods was described in our previous papers. [50,51]

\section{Results and discussion}

In this section we will present the results for human blood plasma from patients without BRCA mutations (control) and patients with BRCA mutations. Figure 1 A and B presents average normalized Raman spectra of human plasma with standard deviation (dark shadows) 
based on 104 single spectra (control) and 460 spectra of patients with BRCA mutations. Figure 1C presents difference Raman spectrum (human blood plasma with BRCA mutation control).

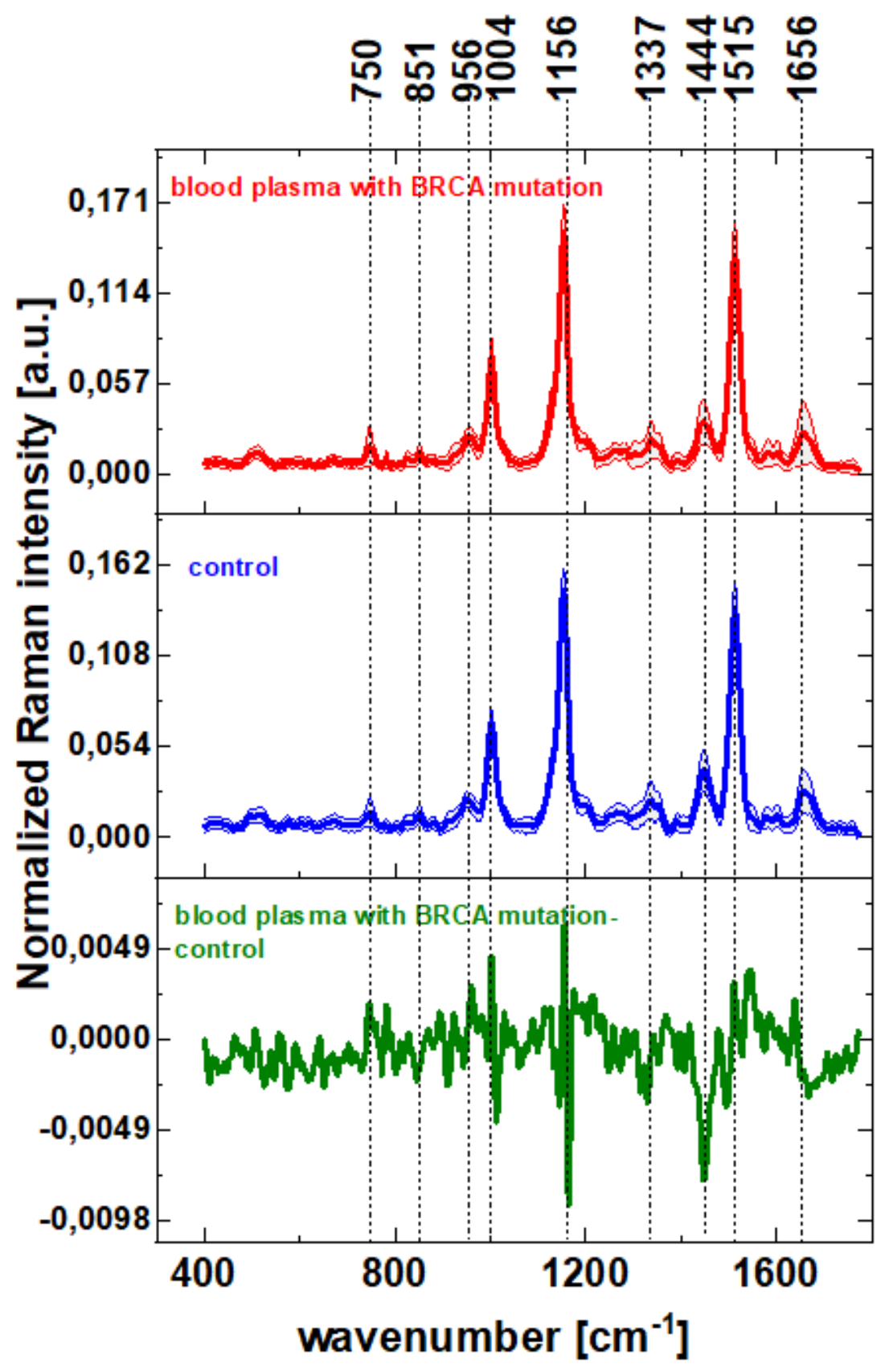

Fig 1 The normalized average Raman spectra typical for: (A) plasma from healthy patients (control) with SD (blue line), (B) plasma from patients with BRCA mutation with SD (red line), (C) the difference spectrum (blood plasma with BRCA - control) (green line) 
One can see from Fig 1 A and B that Raman spectra of the human blood plasma can be characterized by vibrational peaks at: 750, 851, 956, 1004, 1156, 1337, 1444, 1515 and 1656 $\mathrm{cm}^{-1}$. In Table 1 we present the tentative assignments of Raman peaks observed in human blood plasma.

Table 1 Tentative assignments of Raman peaks [52] [53] [54] [55] [56]

\begin{tabular}{|l|l|}
\hline Wavenumber $\left[\mathrm{cm}^{-1}\right]$ & Tentative assignments \\
\hline 750 & Tryptophan, cytochrome c, hemoglobine \\
\hline 851 & tyrosine \\
\hline 956 & hydroxyproline/Collagen backbone \\
\hline 1004 & phenylalanine \\
\hline 1156 & carotenoids \\
\hline 1337 & cytochrome c \\
\hline 1444 & fatty acids, triglycerides $\mathrm{CH}_{2}$ or $\mathrm{CH}_{3}$ \\
\hline 1515 & carotenoids \\
\hline 1656 & Amid I, lipids \\
\hline
\end{tabular}

One can see from the difference spectrum at Fig. 1C that peak at $1004 \mathrm{~cm}^{-1}$ assigned to phenylalanine and $750 \mathrm{~cm}^{-1}$ corresponding to cytochrome c/hemoglobine are positive, what confirms the higher amount of cytochrome $\mathrm{c}$ in blood plasma with BRCA mutation. The positive difference is also observed at $1656 \mathrm{~cm}^{-1}$. This peak is assigned to amid I/lipids which is stronger in the Raman spectra for blood plasma with BRCA mutation (positive correlation in difference spectrum).

Comparing the peaks at $1444 \mathrm{~cm}^{-1}$ assigned to fatty acids/triglycerides $\mathrm{CH}_{2}$ or $\mathrm{CH}_{3}$ one can see that this band is stronger in Raman spectrum for healthy blood plasma (negative correlation in difference spectrum). The same tendency is observed for peaks at $1156 \mathrm{~cm}^{-1}$ and $1515 \mathrm{~cm}-1$ assigned to carotenoids. This observation is consistent with our previous papers for cancer pathology. [51] [57] [58]

In order to visualize chemical similarities and differences between human blood plasma for patients without BRCA mutations and blood plasma samples for patients with BRCA mutation we have evaluated the predictive validity and robustness of Raman spectroscopy by using multivariate statistical methods for data interpretation. We have performed statistical analysis for 564 single spectra. To simplify the task of analyzing a large number of samples 
medRxiv preprint doi: https://doi.org/10.1101/2022.02.21.22271291; this version posted February 22, 2022. The copyright holder for this preprint (which was not certified by peer review) is the author/funder, who has granted medRxiv a license to display the preprint in perpetuity.

All rights reserved. No reuse allowed without permission.

and multidimensional Raman vectors (intensities vs. wavenumbers) were subjected to dimension reduction by means of Partial Least Squares Discriminant Analysis (PLSDA). The PLSDA analysis was applied to the 460 Raman spectra of 85 human blood samples with BRCA mutation and from the 104 Raman spectra of 15 human blood samples without BRCA.

By plotting the principal component scores, similarities between the samples can be revealed. Figure 2 shows the PLSDA score plot for the Raman spectra of the human blood plasma samples with BRCA mutations and for the samples without BRCA mutations.
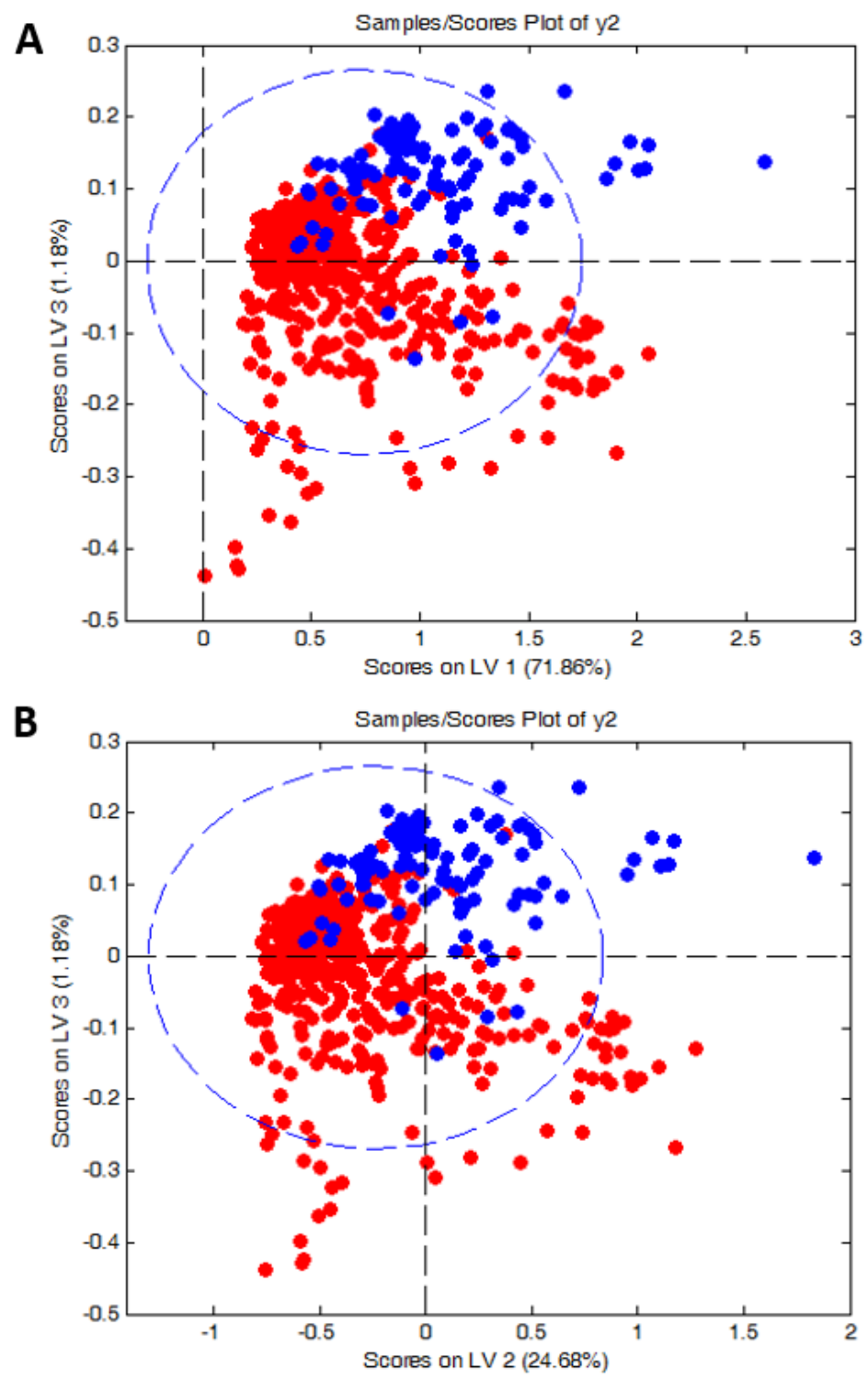

Fig 2. The scores plots obtained from PLSDA for the Raman spectra of blood plasma without BRCA mutations (blue circle) and for Raman spectra of blood plasma with BRCA mutations (red circle) 
One can see from Fig. 2 that evident differences between human blood plasma with BRCA and for human blood plasma without BRCA mutations are revealed. The differences are visible by grouping the results into two separate clusters. Raman spectra for human blood plasma without BRCA mutations (blue circle) are grouped in the right upper area of the plot while the samples from human blood plasma with BRCA mutations (red circle) are grouped in the lower area of the plot. The plot presented on Fig. 2 confirms the differences between samples for human blood plasma without BRCA mutations and for human blood plasma with BRCA mutations.

To understand the molecular information contained in the LV1, LV2 and LV3 we used the loading plots presented in Fig. 3 that reveal the most important characteristic features in the Raman spectra.

Figure 3 shows the loading plots of LV1, LV2 and LV3 versus wavenumbers obtained from PLSDA methods for two classes of spectra typical for human blood plasma without BRCA mutations and for human blood plasma with BRCA mutation. One can see that the loading plots show the most pronounced changes around the characteristic Raman peaks of carotenoids and proteins. 

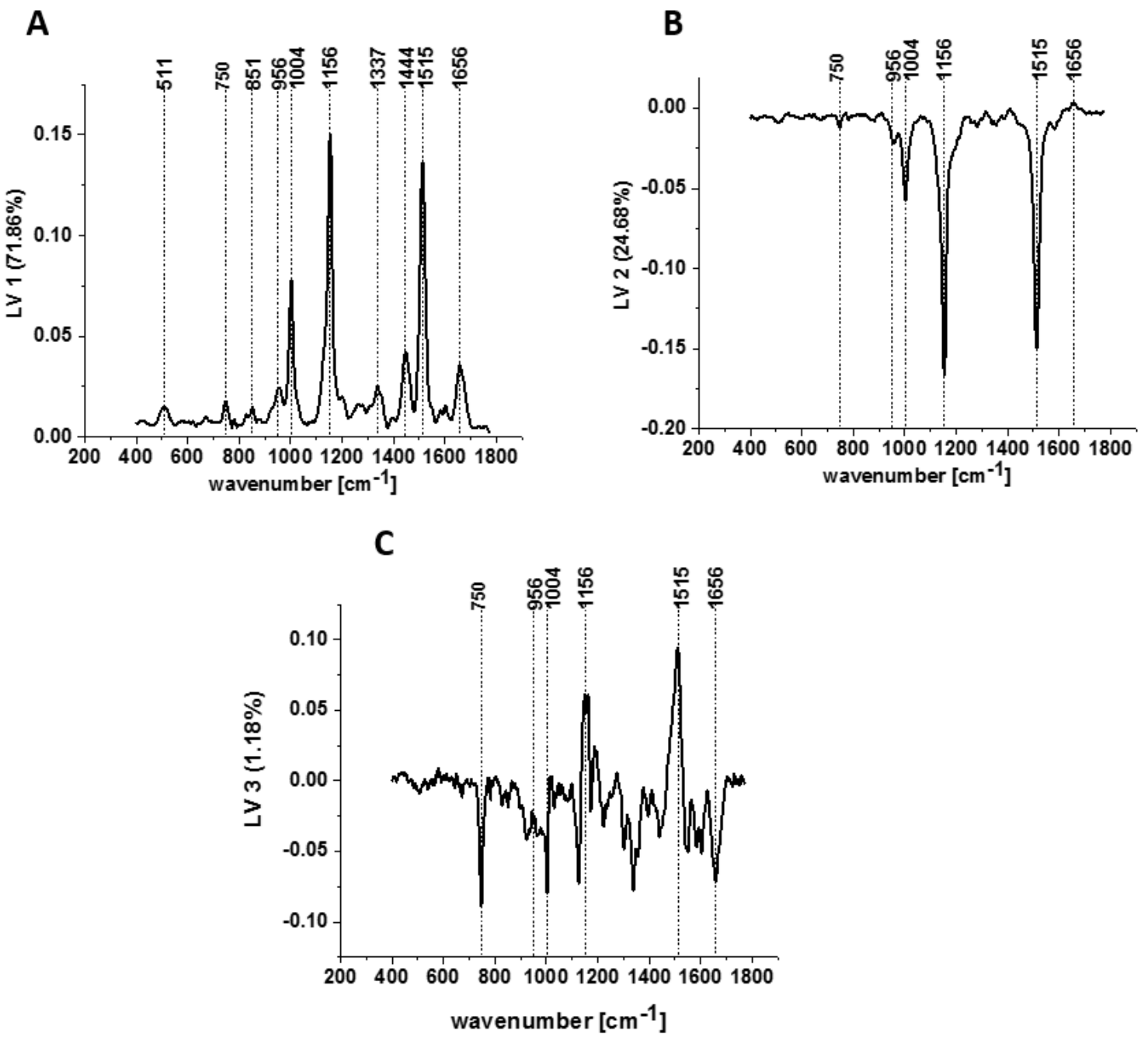

Fig 3. PLSDA loading plot for LV1 (A), LV2 (B), LV3 (C) for the Raman spectra of human blood plasma without BRCA mutations and for Raman spectra of human blood plasma with BRCA mutation.

Once can see from Fig. 3 that the first LV has the contribution of $71.86 \%$, LV2 the contribution of $24.68 \%$ and LV3 the contribution of $1.18 \%$ to variance, respectively. LV1 and LV2 give the dominant account for the maximum variance in the data.

The first latent variable (LV1) is presented in Fig. 3 A. The most characteristic maxima in the loading plot are at $511 \mathrm{~cm}^{-1}, 750 \mathrm{~cm}^{-1}, 851 \mathrm{~cm}^{-1}, 956 \mathrm{~cm}^{-1}, 1004 \mathrm{~cm}^{-1}, 1156 \mathrm{~cm}^{-1}, 1337 \mathrm{~cm}^{-1}$, $1444 \mathrm{~cm}^{-1}, 1515 \mathrm{~cm}^{-1}$, and $1656 \mathrm{~cm}^{-1}$. The second latent variable LV2 (Fig. 3B), reaches its minima at $750 \mathrm{~cm}^{-1}, 956 \mathrm{~cm}^{-1}, 1004 \mathrm{~cm}^{-1}, 1156 \mathrm{~cm}^{-1}, 1515 \mathrm{~cm}^{-1}$ and $1656 \mathrm{~cm}^{-1}$. The third latent variable is presented in Fig. $3 \mathrm{C}$ and reaches its maxima at $1156 \mathrm{~cm}^{-1}$ and $1515 \mathrm{~cm}^{-1}$ and minima at $750 \mathrm{~cm}^{-1,} 1004 \mathrm{~cm}^{-1,} 1656 \mathrm{~cm}^{-1}$.

Table 2 presents the results of calculation of the sensitivity and specificity obtained from PLS-DA method. 
medRxiv preprint doi: https://doi.org/10.1101/2022.02.21.22271291; this version posted February 22, 2022. The copyright holder for this preprint (which was not certified by peer review) is the author/funder, who has granted medRxiv a license to display the preprint in perpetuity.

All rights reserved. No reuse allowed without permission.

Table 2. The values of sensitivity and specificity for calibration and cross validation procedure from PLS-DA analysis.

\begin{tabular}{|c|c|c|}
\hline & Healthy blood plasma & $\begin{array}{c}\text { Blood plasma with BRCA } \\
\text { mutation }\end{array}$ \\
\hline Sensitivity (calibration) & 0.913 & 0.885 \\
\hline Specificity (calibration) & 0.885 & 0.913 \\
\hline Sensitivity (cross validation) & 0.900 & 0.865 \\
\hline Specificity (cross validation) & 0.865 & 0.900 \\
\hline
\end{tabular}

Figure 4 presents ROC curves (Receiver Operating Characteristic) curves for blood plasma sample without BRCA mutations and for blood plasma sample with BRCA mutations. Figure 4 confirms high potential of Raman spectroscopy to differentiate between patients without BRCA mutations and with BRCA mutations .

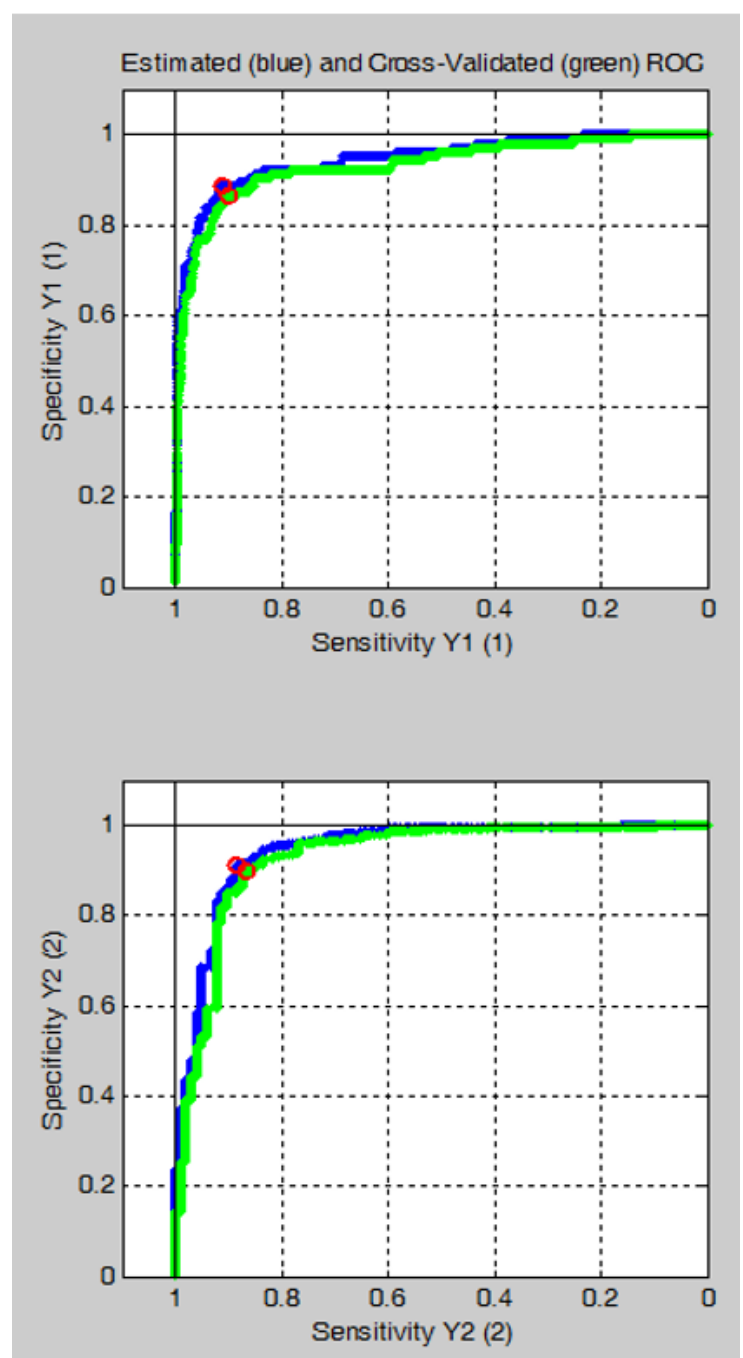

Fig 4. ROC curves obtained from the PLS-DA analysis for two classes of Raman spectra assigned to blood plasma without BRCA mutations and blood plasma with BRCA mutation. 


\section{Conclusions}

In this paper we used Raman spectroscopy to monitor BRCA mutations in human blood plasma. Raman spectroscopy and PLSDA have been shown to be excellent tool for the diagnosis of breast BRCA mutations. Raman spectroscopy and chemometric method have been successfully applied to characterize and differentiate-human blood plasma without BRCA mutations and human blood plasma with BRCA mutation. The results presented in this paper suggest that Raman biomarkers in the near future can provide additional insight into the biology of human blood plasma. The differentiation by Raman spectroscopy between blood plasma without BRCA mutations and blood plasma with BRCA mutations is important because the high specificity and sensitivity can lead to genomic breast diagnosis. Our results can help implement Raman spectroscopy as a tool for blood analysis to investigate BRCA mutations.

\section{Acknowledgement}

This work was supported by the National Science Centre of Poland (Narodowe Centrum Nauki, UMO-2019/33/B/ST4/01961).

\section{CRediT authorship contribution statement}

Conceptualization: H.A., M.K.; Funding acquisition: H.A., Investigation: M.K., B.R-P., Methodology: M.K., B.R-P.; Writing-original draft: M.K., H.A.; Manuscript editing: M.K., H.A. All authors have read and agreed to the published version of the manuscript.

\section{References}

[1] D. Basu, R. Kulkarni, Overview of blood components and their preparation, Indian J. Anaesth. 58 (2014) 529-537. https://doi.org/10.4103/0019-5049.144647.

[2] C. Weiss, W. Jelkmann, Functions of the Blood, in: R.F. Schmidt, G. Thews (Eds.), Hum. Physiol., Springer Berlin Heidelberg, Berlin, Heidelberg, 1989: pp. 402-438. https://doi.org/10.1007/978-3-642-73831-9_18.

[3] V. Kuhn, L. Diederich, T.C.S. Keller, C.M. Kramer, W. Lückstädt, C. Panknin, T. Suvorava, B.E. Isakson, M. Kelm, M.M. Cortese-Krott, Red Blood Cell Function and Dysfunction: Redox Regulation, Nitric Oxide Metabolism, Anemia, Antioxidants Redox Signal. 26 (2017) 718-742. https://doi.org/10.1089/ars.2016.6954.

[4] M. Seyoum, B. Enawgaw, M. Melku, Human blood platelets and viruses: defense mechanism and role in the removal of viral pathogens, Thromb. J. 16 (2018) 16. https://doi.org/10.1186/s12959-018-0170-8.

[5] M.S. Kirkman, H. Mahmud, M.T. Korytkowski, Intensive Blood Glucose Control and Vascular Outcomes in Patients with Type 2 Diabetes Mellitus, Endocrinol. Metab. 
Clin. North Am. 47 (2018) 81-96. https://doi.org/10.1016/j.ecl.2017.10.002.

[6] Q. Feng, M. Yu, N.B. Kiviat, Molecular biomarkers for cancer detection in blood and bodily fluids, Crit. Rev. Clin. Lab. Sci. 43 (2006) 497-560. https://doi.org/10.1080/10408360600922632.

[7] P.S. Mitchell, R.K. Parkin, E.M. Kroh, B.R. Fritz, S.K. Wyman, E.L. PogosovaAgadjanyan, A. Peterson, J. Noteboom, K.C. O’Briant, A. Allen, D.W. Lin, N. Urban, C.W. Drescher, B.S. Knudsen, D.L. Stirewalt, R. Gentleman, R.L. Vessella, P.S. Nelson, D.B. Martin, M. Tewari, Circulating microRNAs as stable blood-based markers for cancer detection, Proc. Natl. Acad. Sci. U. S. A. 105 (2008) 10513-10518. https://doi.org/10.1073/pnas.0804549105.

[8] V. El-Khoury, A. Schritz, S.Y. Kim, A. Lesur, K. Sertamo, F. Bernardin, K. Petritis, P. Pirrotte, C. Selinsky, J.R. Whiteaker, H. Zhang, J.J. Kennedy, C. Lin, L.W. Lee, P. Yan, N.L. Tran, L.J. Inge, K. Chalabi, G. Decker, R. Bjerkvig, A.G. Paulovich, G. Berchem, Y.J. Kim, Identification of a blood-based protein biomarker panel for lung cancer detection, Cancers (Basel). 12 (2020) 1-15. https://doi.org/10.3390/cancers12061629.

[9] A.M. Sofie Berghuis, H. Koffijberg, J. Prakash, L.W.M.M. Terstappen, M.J. Ijzerman, Detecting blood-based biomarkers in metastatic breast cancer: A systematic review of their current status and clinical utility, Int. J. Mol. Sci. 18 (2017) 1-45. https://doi.org/10.3390/ijms18020363.

[10] A. Kazarian, O. Blyuss, G. Metodieva, A. Gentry-Maharaj, A. Ryan, E.M. Kiseleva, O.M. Prytomanova, I.J. Jacobs, M. Widschwendter, U. Menon, J.F. Timms, Testing breast cancer serum biomarkers for early detection and prognosis in pre-diagnosis samples, Br. J. Cancer. 116 (2017) 501-508. https://doi.org/10.1038/bjc.2016.433.

[11] H. Hampel, S.E. O’Bryant, J.L. Molinuevo, H. Zetterberg, C.L. Masters, S. Lista, S.J. Kiddle, R. Batrla, K. Blennow, Blood-based biomarkers for Alzheimer disease: mapping the road to the clinic, Nat. Rev. Neurol. 14 (2018) 639-652. https://doi.org/10.1038/s41582-018-0079-7.

[12] N. Harbeck, F. Penault-Llorca, J. Cortes, M. Gnant, N. Houssami, P. Poortmans, K. Ruddy, J. Tsang, F. Cardoso, Breast cancer, 2019. https://doi.org/10.1038/s41572-0190111-2.

[13] D.P. Atchley, C.T. Albarracin, A. Lopez, V. Valero, C.I. Amos, A.M. GonzalezAngulo, G.N. Hortobagyi, B.K. Arun, Clinical and pathologic characteristics of patients with BRCA-positive and BRCA-negative breast cancer, J. Clin. Oncol. 26 (2008) 4282-4288. https://doi.org/10.1200/JCO.2008.16.6231.

[14] D.K. Owens, K.W. Davidson, A.H. Krist, M.J. Barry, M. Cabana, A.B. Caughey, C.A. Doubeni, J.W. Epling, M. Kubik, C.S. Landefeld, C.M. Mangione, L. Pbert, M. Silverstein, M.A. Simon, C.W. Tseng, J.B. Wong, Risk Assessment, Genetic Counseling, and Genetic Testing for BRCA -Related Cancer: US Preventive Services Task Force Recommendation Statement, JAMA - J. Am. Med. Assoc. 322 (2019) 652665. https://doi.org/10.1001/jama.2019.10987.

[15] S.A. Narod, BRCA mutations in the management of breast cancer: The state of the art, Nat. Rev. Clin. Oncol. 7 (2010) 702-707. https://doi.org/10.1038/nrclinonc.2010.166.

[16] K. Alsop, S. Fereday, C. Meldrum, A. DeFazio, C. Emmanuel, J. George, A. Dobrovic, 
M.J. Birrer, P.M. Webb, C. Stewart, M. Friedlander, S. Fox, D. Bowtell, G. Mitchell, BRCA mutation frequency and patterns of treatment response in BRCA mutationpositive women with ovarian cancer: A report from the Australian ovarian cancer study group, J. Clin. Oncol. 30 (2012) 2654-2663. https://doi.org/10.1200/JCO.2011.39.8545.

[17] S. Hedau, M. Batra, U.R. Singh, A.C. Bharti, A. Ray, B.C. Das, Expression of BRCA1 and BRCA2 proteins and their correlation with clinical staging in breast cancer, $\mathrm{J}$. Cancer Res. Ther. 11 (2015) 158-163. https://doi.org/10.4103/0973-1482.140985.

[18] E.A. Rakha, S.E. El-Sheikh, M.A. Kandil, M.E. El-Sayed, A.R. Green, I.O. Ellis, Expression of BRCA1 protein in breast cancer and its prognostic significance, Hum. Pathol. 39 (2008) 857-865. https://doi.org/10.1016/j.humpath.2007.10.011.

[19] Z. Wang, J. Zhang, Y. Zhang, Q. Deng, H. Liang, Expression and mutations of BRCA in breast cancer and ovarian cancer: Evidence from bioinformatics analyses, Int. J. Mol. Med. 42 (2018) 3542-3550. https://doi.org/10.3892/ijmm.2018.3870.

[20] F. Al-Mulla, M. Abdulrahman, G. Varadharaj, N. Akhter, J.T. Anim, BRCA1 gene expression in breast cancer: A correlative study between real-time RT-PCR and immunohistochemistry, J. Histochem. Cytochem. 53 (2005) 621-629. https://doi.org/10.1369/jhc.4A6544.2005.

[21] J.L. Andres, S. Fan, G.J. Turkel, J.A. Wang, N.F. Twu, R.Q. Yuan, K. Lamszus, I.D. Goldberg, E.M. Rosen, Regulation of BRCA1 and BRCA2 expression in human breast cancer cells by DNA-damaging agents, Oncogene. 16 (1998) 2229-2241. https://doi.org/10.1038/sj.onc.1201752.

[22] H. Chen, J. Wu, Z. Zhang, Y. Tang, X. Li, S. Liu, S. Cao, X. Li, Association between BRCA status and triple-negative breast cancer: A meta-analysis, Front. Pharmacol. 9 (2018) 1-8. https://doi.org/10.3389/fphar.2018.00909.

[23] P.L. Welcsh, M.C. King, BRCA1 and BRCA2 and the genetics of breast and ovarian cancer, Hum. Mol. Genet. 10 (2001) 705-713. https://doi.org/10.1093/hmg/10.7.705.

[24] E. Gross, N. Arnold, J. Goette, U. Schwarz-Boeger, M. Kiechle, A comparison of BRCA1 mutation analysis by direct sequencing, SSCP and DHPLC, Hum. Genet. 105 (1999) 72-78. https://doi.org/10.1007/s004399900092.

[25] T. Wagner, D. Stoppa-Lyonnet, E. Fleischmann, D. Muhr, S. Pagès, T. Sandberg, V. Caux, R. Moeslinger, G. Langbauer, A. Borg, P. Oefner, Denaturing high-performance liquid chromatography detects reliably BRCA1 and BRCA2 mutations, Genomics. 62 (1999) 369-376. https://doi.org/10.1006/geno.1999.6026.

[26] J. Roth, C. Peer, B. Mannargudi, H. Swaisland, J.-M. Lee, E. Kohn, W. Figg, A Sensitive and Robust Ultra HPLC Assay with Tandem Mass Spectrometric Detection for the Quantitation of the PARP Inhibitor Olaparib (AZD2281) in Human Plasma for Pharmacokinetic Application, Chromatography. 1 (2014) 82-95. https://doi.org/10.3390/chromatography1020082.

[27] V. D’Argenio, M.V. Esposito, A. Telese, V. Precone, F. Starnone, M. Nunziato, P. Cantiello, M. Iorio, E. Evangelista, M. D'Aiuto, A. Calabrese, G. Frisso, G. D’Aiuto, F. Salvatore, The molecular analysis of BRCA1 and BRCA2: Next-generation sequencing supersedes conventional approaches, Clin. Chim. Acta. 446 (2015) 221225. https://doi.org/10.1016/j.cca.2015.03.045. 
[28] A.J. Wallace, New challenges for BRCA testing: A view from the diagnostic laboratory, Eur. J. Hum. Genet. 24 (2016) S10-S18.

https://doi.org/10.1038/ejhg.2016.94.

[29] M.A. Ewelina Szczerba, Katarzyna Kaminska, Tomasz Mierzwa, Marcin Misiek, Janusz Kowalewski, Lewandowska, BRCA1 / 2 Mutation Detection in the Tumor Tissue from, Genes (Basel). 12 (2021).

[30] L.R. Allain, T. Vo-Dinh, Surface-enhanced Raman scattering detection of the breast cancer susceptibility gene BRCA1 using a silver-coated microarray platform, Anal. Chim. Acta. 469 (2002) 149-154. https://doi.org/10.1016/S0003-2670(01)01537-9.

[31] M. Culha, D. Stokes, L.R. Allain, T. Vo-Dinh, Surface-Enhanced Raman Scattering Substrate Based on a Self-Assembled Monolayer for Use in Gene Diagnostics, Anal. Chem. 75 (2003) 6196-6201. https://doi.org/10.1021/ac0346003.

[32] K. Beton, P. Wysocki, B. Brozek-Pluska, Mevastatin in colon cancer by spectroscopic and microscopic methods - Raman imaging and AFM studies, Spectrochim. Acta - Part A Mol. Biomol. Spectrosc. 270 (2022) 120726. https://doi.org/10.1016/j.saa.2021.120726.

[33] K. V. Konstantinos, P. Panagiotis, V.T. Antonios, P. Agelos, N. V. Argiris, PCRSSCP: A method for the molecular analysis of genetic diseases, Mol. Biotechnol. 38 (2008) 155-163. https://doi.org/10.1007/s12033-007-9006-7.

[34] D.G.R. Evans, D.M. Eccles, N. Rahman, K. Young, M. Bulman, E. Amir, A. Shenton, A. Howell, F. Lalloo, A new scoring system for the chances of identifying a BRCA1/2 mutation outperforms existing models including BRCAPRO, J. Med. Genet. 41 (2004) 474-480. https://doi.org/10.1136/jmg.2003.017996.

[35] N. Mahdieh, B. Rabbani, An overview of mutation detection methods in genetic disorders, Iran. J. Pediatr. 23 (2013) 375-388.

[36] Y. Xue, A. Ankala, W.R. Wilcox, M.R. Hegde, Solving the molecular diagnostic testing conundrum for Mendelian disorders in the era of next-generation sequencing: Single-gene, gene panel, or exome/genome sequencing, Genet. Med. 17 (2015) 444 451. https://doi.org/10.1038/gim.2014.122.

[37] V. Shashi, A. McConkie-Rosell, B. Rosell, K. Schoch, K. Vellore, M. McDonald, Y.H. Jiang, P. Xie, A. Need, D.B. Goldstein, The utility of the traditional medical genetics diagnostic evaluation in the context of next-generation sequencing for undiagnosed genetic disorders, Genet. Med. 16 (2014) 176-182. https://doi.org/10.1038/gim.2013.99.

[38] B.M. Crossley, J. Bai, A. Glaser, R. Maes, E. Porter, M.L. Killian, T. Clement, K. Toohey-Kurth, Guidelines for Sanger sequencing and molecular assay monitoring, J. Vet. Diagnostic Investig. 32 (2020) 767-775. https://doi.org/10.1177/1040638720905833.

[39] B. Sikkema-Raddatz, L.F. Johansson, E.N. de Boer, R. Almomani, L.G. Boven, M.P. van den Berg, K.Y. van Spaendonck-Zwarts, J.P. van Tintelen, R.H. Sijmons, J.D.H. Jongbloed, R.J. Sinke, Targeted Next-Generation Sequencing can Replace Sanger Sequencing in Clinical Diagnostics, Hum. Mutat. 34 (2013) 1035-1042. https://doi.org/10.1002/humu.22332. 
[40] A. Kluska, A. Balabas, A. Paziewska, M. Kulecka, D. Nowakowska, M. Mikula, J. Ostrowski, New recurrent BRCA1/2 mutations in Polish patients with familial breast/ovarian cancer detected by next generation sequencing, BMC Med. Genomics. 8 (2015) 1-9. https://doi.org/10.1186/s12920-015-0092-2.

[41] H.W. Tuffaha, A. Mitchell, R.L. Ward, L. Connelly, J.R.G. Butler, S. Norris, P.A. Scuffham, Cost-effectiveness analysis of germ-line BRCA testing in women with breast cancer and cascade testing in family members of mutation carriers, Genet. Med. 20 (2018) 985-994. https://doi.org/10.1038/gim.2017.231.

[42] S. Richards, N. Aziz, S. Bale, D. Bick, S. Das, J. Gastier-Foster, W.W. Grody, M. Hegde, E. Lyon, E. Spector, K. Voelkerding, H.L. Rehm, Standards and guidelines for the interpretation of sequence variants: A joint consensus recommendation of the American College of Medical Genetics and Genomics and the Association for Molecular Pathology, Genet. Med. 17 (2015) 405-424. https://doi.org/10.1038/gim.2015.30.

[43] S. Behjati, P.S. Tarpey, What is next generation sequencing?, Arch. Dis. Child. Educ. Pract. Ed. 98 (2013) 236-238. https://doi.org/10.1136/archdischild-2013-304340.

[44] M.A. Jones, D. Rhodenizer, C. da Silva, I.J. Huff, L. Keong, L.J.H. Bean, B. Coffee, C. Collins, A.K. Tanner, M. He, M.R. Hegde, Molecular diagnostic testing for congenital disorders of glycosylation (CDG): Detection rate for single gene testing and next generation sequencing panel testing, Mol. Genet. Metab. 110 (2013) 78-85. https://doi.org/10.1016/j.ymgme.2013.05.012.

[45] D. Qin, Next-generation sequencing and its clinical application, Cancer Biol. Med. 16 (2019) 4-10. https://doi.org/10.20892/j.issn.2095-3941.2018.0055.

[46] C. Hömig-Hölzel, S. Savola, Multiplex Ligation-dependent Probe Amplification (MLPA) in tumor diagnostics and prognostics, Diagnostic Mol. Pathol. 21 (2012) 189206. https://doi.org/10.1097/PDM.0b013e3182595516.

[47] A. Bozsik, T. Pócza, J. Papp, T. Vaszkó, H. Butz, A. Patócs, E. Oláh, Complex characterization of germline large genomic rearrangements of the BRCA1 and BRCA2 genes in high-risk breast cancer patients-novel variants from a large national center, Int. J. Mol. Sci. 21 (2020) 1-17. https://doi.org/10.3390/ijms21134650.

[48] S. Engert, B. Wappenschmidt, B. Betz, K. Kast, M. Kutsche, H. Hellebrand, T.O. Goecke, M. Kiechle, D. Niederacher, R.K. Schmutzler, A. Meindl, MLPA screening in the BRCA1 gene from 1,506 German hereditary breast cancer cases: Novel deletions, frequent involvement of exon 17, and occurrence in single early-onset cases, Hum. Mutat. 29 (2008) 948-958. https://doi.org/10.1002/humu.20723.

[49] A.A. Durmaz, E. Karaca, U. Demkow, G. Toruner, J. Schoumans, O. Cogulu, Evolution of genetic techniques: Past, present, and beyond, Biomed Res. Int. 2015 (2015). https://doi.org/10.1155/2015/461524.

[50] M. Kopec, H. Abramczyk, The role of pro- and antiangiogenic factors in angiogenesis process by Raman spectroscopy, Spectrochim. Acta Part A Mol. Biomol. Spectrosc. 268 (2022) 120667. https://doi.org/10.1016/j.saa.2021.120667.

[51] J. Surmacki, B. Brozek-Pluska, R. Kordek, H. Abramczyk, The lipid-reactive oxygen species phenotype of breast cancer. Raman spectroscopy and mapping, PCA and PLSDA for invasive ductal carcinoma and invasive lobular carcinoma. Molecular 
tumorigenic mechanisms beyond Warburg effect, Analyst. 140 (2015) 2121-2133. https://doi.org/10.1039/c4an01876a.

[52] H. Abramczyk, J.M. Surmacki, B. Brozek-Pluska, Redox state changes of mitochondrial cytochromes in brain and breast cancers by Raman spectroscopy and imaging, J. Mol. Struct. 1252 (2022) 132134.

https://doi.org/10.1016/j.molstruc.2021.132134.

[53] H. Abramczyk, J.M. Surmacki, B. Brozek-Pluska, M. Kopec, Revision of Commonly Accepted Warburg Mechanism of Cancer Development $\square$ : Redox-Sensitive Mitochondrial Cytochromes in Breast and Brain Cancers by Raman Imaging, Cancers (Basel). (2021).

[54] M. Abramczyk, H, Brozek-Pluska B, Kopec, Double face of cytochrome c in cancers by Raman imaging, Sci. Rep. (2022) 1-11. https://doi.org/10.1038/s41598-022-048030 .

[55] H. Abramczyk, B. Brozek-Pluska, M. Kopec, J. Surmacki, M. Błaszczyk, M. Radek, Redox imbalance and biochemical changes in cancer by probing redox-sensitive mitochondrial cytochromes in label-free visible resonance raman imaging, Cancers (Basel). 13 (2021). https://doi.org/10.1101/2020.12.03.409359.

[56] M. Kopec, M. Błaszczyk, M. Radek, H. Abramczyk, Raman imaging and statistical methods for analysis various type of human brain tumors and breast cancers, Spectrochim. Acta - Part A Mol. Biomol. Spectrosc. 262 (2021) 120091. https://doi.org/10.1016/j.saa.2021.120091.

[57] B. Brozek-Pluska, M. Kopec, J. Surmacki, H. Abramczyk, Raman microspectroscopy of noncancerous and cancerous human breast tissues. Identification and phase transitions of linoleic and oleic acids by Raman low-temperature studies, Analyst. 140 (2015) 2134-2143. https://doi.org/10.1039/c4an01877j.

[58] B. Brozek-Pluska, J. Musial, R. Kordek, E. Bailo, T. Dieing, H. Abramczyk, Raman spectroscopy and imaging: Applications in human breast cancer diagnosis, Analyst. 137 (2012) 3773-3780. https://doi.org/10.1039/c2an16179f. 